\title{
Alteration of Migration and Maturation of Dendritic Cells and T-Cell Depletion in the Course of Experimental Trypanosoma cruzi Infection
}

\author{
Damien Chaussabel, Bernard Pajak, Vincent Vercruysse, Cyrille Bisseyé, \\ Virginie Garzé, Mohammed Habib, Michel Goldman, Muriel Moser, and \\ Bernard Vray
}

Laboratoire d'Immunologie Expérimentale (DC, $\mathrm{V}, \mathrm{CB}, \mathrm{MH}, \mathrm{MG}, \mathrm{BV})$, Faculté de Médecine, and Département de Biologie des Organismes (DC, BV), Faculté des Sciences, Université Libre de Bruxelles, Brussels, and Laboratoire de Physiologie Animale (BP, VG, MM), Département de Biologie et de Médecine Moléculaires, Université Libre de Bruxelles, Gosselies, Belgium

\begin{abstract}
SUMMARY: Trypanosoma cruzi, the etiologic agent of Chagas disease, induces infection that affects most immunocompetent cells. However, its effect on dendritic cells (DC) is still unknown in vivo. In this report, we show, by immunohistochemical staining, that $T$. cruzi infection triggers a huge increase in the number of CD11c ${ }^{+}$DC in the spleen of infected mice at Days 14 and 21 post-inoculation (pi). In mice reaching the chronic phase (starting on Day 35 pi), the number of splenic DC (sDC) returned progressively to normal (ending on Day $98 \mathrm{pi}$ ). In the spleens of noninfected mice, most of the CD8 $\alpha^{+} \mathrm{CD} 11 \mathrm{c}^{+}$and CD8 $\alpha^{-} \mathrm{CD} 11 \mathrm{c}^{+}$ DC were found in the red pulp and the marginal and T-cell zones. However, starting on Day 14 pi, a progressive decline of CD $8 \alpha^{+} \mathrm{CD}_{11 \mathrm{c}^{+}}$was observed. In addition, sDC expressed low levels of the costimulatory molecule B7.2 at Days 14 and 21 pi, suggesting that they remained immature in the course of the infection. As expected, in lipopolysaccharide-treated and noninfected mice, the expression of B7.2 molecules was sharply up-regulated on SDC that migrated toward the T-cell zone. In contrast, upon lipopolysaccharide stimulation, sDC from $T$. cruzi-infected mice did not migrate toward the T-cell zone nor did they undergo maturation. Finally, white pulp was severely depleted in both $\mathrm{CD}^{+}$and $\mathrm{CD} 8^{+} \mathrm{T}$ cells at the peak of infection. Taken together, these results indicate that profound alterations of migration and maturation of SDC and depletion/redistribution of T cells occur during the acute phase of $T$. cruzi infection and could be part of another strategy to escape immune surveillance and to persist in the host. (Lab Invest 2003, 83:1373-1382).
\end{abstract}

$D$ evelopment of a specific and protective immune response against pathogens first depends on their interactions with dendritic cells (DC), which act as roving sentinels of the immune system. DC are found in most tissues and organs and constitute a complex system of professional APC (Mellman and Steinman, 2001). Immature DC capture pathogens or pathogenderived antigens. Then, upon activation by microbial components and/or cytokines, DC migrate to lymph nodes draining the site of invasion and spleen. During their migration, they undergo a process of maturation, losing their capacity to capture and process antigens but increasing their expression of $\mathrm{MHC}$ class II, co-

DOI: 10.1097/01.LAB.0000087587.93781.6F

Received July 7, 2003.

The two first authors have contributed equally to this work. This work was supported by grants from Action de Recherche Concertée de la Communauté Française de Belgique, Centre de Recherche Interuniversitaire en Vaccinologie (CRIV), the Fonds Emile Defay, and the Fondation de Meurs-François.

Address reprint requests to: Prof. B. Vray, Laboratoire d'Immunologie Expérimentale (CP 615), Faculté de Médecine, Université Libre de Bruxelles, 808 route de Lennik, B-1070 Brussels, Belgium. E-mail: bvray@ulb.ac.be stimulatory (CD40, CD80, CD86), and adhesion molecules (CD54) (Steinman et al, 1997). Finally, they differentiate into fully potent $A P C$ and they prime rare naïve $T$ cells expressing the relevant $T$ cell receptors and induce their differentiation and proliferation (Lanzavecchia and Sallusto, 2000).

Trypanosoma cruzi is a hemoflagellate parasitic protozoa. It infects humans and domestic and wild mammals and is the etiologic agent of Chagas disease (Tarleton and Zhang, 1999). Experimental infection of $\mathrm{BALB} / \mathrm{c}$ mice mimics the human disease. It displays an acute phase with parasitemia and mortality followed by a chronic phase during which parasites become undetectable in peripheral blood while persisting in tissues and inducing pathologic manifestations (Marinho et al, 1999). As is the case for many other pathogens, their evolutionary adaptation allows them to evade the immune system, and $T$. cruzi infection is mainly characterized by dramatic immunodeficiency. Both T cells (Lopes and DosReis, 1996; Tarleton, 1988) and adherent cells (Abrahamsohn and Coffman, 1995; Cerrone et al, 1992) are implicated in this immune hyporesponsiveness together with the down-regulation of IL-2 production, nitric oxidemediated inhibition of lymphoproliferation, and B-cell 
polyclonal activation (Cardillo et al, 1998; el Bouhdidi et al, 1994; Kierszenbaum and Sztein, 2001; Kierszenbaum et al, 1998).

Recently, we have shown that human DC can be infected in vitro by $T$. cruzi trypomastigotes. As a functional consequence, the $T$. cruzi infection inhibited lipopolysaccharide (LPS)-mediated maturation of DC, their expression of MHC class I and II molecules, and antigen presentation to specific $\mathrm{CD}^{+} \mathrm{T}$ lymphocytes (Van Overtvelt et al, 1999, 2002). These data prompted us to investigate the consequences of $T$. cruzi infection in vivo on the number, migration, and maturation of murine sDC and on T-cell populations.

\section{Results}

\section{T. cruzi Infection Increases the Number of $s D C$}

The acute phase of $T$. cruzi infection is generally characterized by splenomegaly, increased spleen cellularity with blastic lymphoid cells in the red and white pulp, hyperplasia of germinal centers of the lymphoid follicles, B and T lymphocyte proliferation, enhancement of Ly6G $(\mathrm{Gr} 1(+)) \mathrm{CD} 11 \mathrm{~b}(+)$ immature myeloid suppressor cells, and the presence of a variable number of parasites (Andrade et al, 1985; Camargo et al, 1991; Goni et al, 2002; Guarner et al, 2001; Minoprio et al, 1989; Tarleton and Kuhn, 1983; Younes-Chennoufi et al, 1988). However, to our knowledge and despite the cardinal role of sDC, modifications in their number and their migration and maturation processes have not yet been documented.

Immunohistochemical studies were thus performed on spleen sections to identify the presence of SDC in situ (Fig. 1). For this, we used the CD11c marker that is expressed on myeloid and lymphoid DC (for review see Liu, 2001). At the beginning of $T$. cruzi infection [at $3,6,12$, and 24 hours post-inoculation (pi)], the amount of $\mathrm{CD}_{11 \mathrm{c}^{+}} \mathrm{sDC}$ was similar to that observed in the spleens from control mice (data not shown). In contrast, at Days 7, 14, and $21 \mathrm{pi}$, a progressive and important increase in the number of SDC was found. However, the distribution of sDC among the red pulp and the marginal and T-cell zones was not modified. In light of this striking enhancement of sDC number, these cells were isolated from the spleens of noninfected and infected mice at Day 21 pi and counted. The mean number of CD11 ${ }^{+}$sDC per spleen reached $0.73 \pm 0.44 \times 10^{6} \mathrm{sDC}$ for noninfected mice $(n=15)$ and $2.85 \pm 1.39 \times 10^{6}$ for sDC-infected mice $(n=10)$ at Day 21 pi $(p<0.001$, nonparametric Mann-Whitney $U$ test). Interestingly, both sDC number and parasitemia increased simultaneously, starting on Day 14 and peaking at Day 21 pi. Kinetics of parasitemia and mortality rate (Fig. 6A) were similar to that previously described (Olivares et al, 1996). Furthermore, the increase in the sDC number corresponds to arising splenomegaly. The mean weights of spleens were $109.7 \pm 18.9 \mathrm{mg}$ for noninfected mice $(n=9)$ and $620.8 \pm 88.9 \mathrm{mg}$ for infected mice $(n=5)$ at Day $21 \mathrm{pi}$ ( $p<0.003$, nonparametric Mann-Whitney $U$ test). This splenomegaly is in line with previous reports (Andrade et al, 1985; Camargo et al, 1991). Thus, from Day 0 until Day 21 pi, mean weight of spleens was increased by 6 -fold and mean number of SDC was increased by 4-fold, indicating that SDC are clearly involved in increased cellularity of spleens from infected mice together with other spleen cells. In surviving mice reaching the chronic phase, splenomegaly slowly regressed and the number of SDC returned progressively to normal, starting on Day 35. A normal pattern of SDC was observed on Day 98 pi (data not shown).

\section{T. cruzi Infection Down-Regulates the CD8 $\alpha^{+}$Subclass of $s D C$}

$\mathrm{CD} 8 \alpha^{+}$and $\mathrm{CD} 8 \alpha^{-}$subclasses of SDC also have a central role because they drive the development of $T$ helper 1 and Thelper 2 lymphocytes, respectively, and consequently the type 1 (or type 2) immune response (Maldonado-Lopez et al, 1999). The type 1 immune response is thought to have a protective role in $T$. cruzi infection through the production of $\mathrm{T}$ helper 1 cytokines such as IL-12, IFN- $\gamma$, and TNF (Chaussabel et al, 1999). sDC were thus further investigated by staining CD8 $\alpha^{+}$cells in blue and CD11c ${ }^{+}$cells in red so that $\mathrm{CD} 8 \alpha^{+} \mathrm{CD}_{11 \mathrm{c}^{+}} \mathrm{sDC}$ and $\mathrm{CD} 8 \alpha^{-} \mathrm{CD} 11 \mathrm{c}^{+} \mathrm{sDC}$ were stained in purple and in red, respectively (Fig. 2). In the spleens of noninfected mice, both $C D 8 \alpha^{+}$CD $11 c^{+} D C$ and $\mathrm{CD} 8 \alpha^{-}$CD $11 \mathrm{c}^{+} \mathrm{DC}$ were found in the red pulp in the marginal and T-cell zones. At Day $14 \mathrm{pi}$, most of the $\mathrm{CD} 8 \alpha^{+} \mathrm{CD} 11 \mathrm{c}^{+} \mathrm{sDC}$ and $\mathrm{CD} 8 \alpha^{-} \mathrm{CD} 11 \mathrm{c}^{+} \mathrm{sDC}$ were found in the red pulp and in the marginal zone, but $\mathrm{CD} 8 \alpha^{+} \mathrm{CD} 11 \mathrm{c}^{+} \mathrm{sDC}$ were no longer found in the T-cell zone. At Day $21 \mathrm{pi}$, all $\mathrm{CD} 8 \alpha^{+} \mathrm{CD} 11 \mathrm{c}^{+} \mathrm{sDC}$ completely disappeared, whereas $\mathrm{CD} 8 \alpha^{-} \mathrm{CD} 11 \mathrm{c}^{+}$ sDC were still clearly present. These observations suggest $T$. cruzi infection down-regulates the CD8 $\alpha^{+} \mathrm{CD}_{11 \mathrm{C}^{+}} \mathrm{sDC}$ subpopulation and thus could impair the protective type 1 response mounted by mammalian host.

\section{T. cruzi Infection Does Not Induce the Maturation of sDC}

Upon microbial stimulation, immature SDC situated in the marginal zone mature after migration to the T-cell zone (De Smedt et al, 1996). Most pathogens trigger this migration/maturation process of DC: Borrelia burgdorferi (Filgueira et al, 1996), Leishmania spp (Gorak et al, 1998; von Stebut et al, 2000), and Mycobacterium (Henderson et al, 1997; Inaba et al, 1993). This point was thus further investigated in the course of $T$. cruzi infection, by staining $\mathrm{CD}_{11 \mathrm{c}^{+}}$cells in red and $\mathrm{B} .2^{+}$cells in blue (Fig. 3). Immunohistochemical study did not show any purple stained cells $\left(\mathrm{CD} 11 \mathrm{c}^{+} \mathrm{B} 7.2^{+} \mathrm{sDC}\right)$, suggesting that no migration nor maturation of sDC occurred at Days 14 and 21 pi (Fig. 3 , a to c). This was confirmed by flow cytometry showing that B7.2 expression was only weakly enhanced at Days 14 and 21 pi (data not shown). These observations indicate that the migration/maturation step of SDC did not occur in the course of $T$. cruzi infection. 

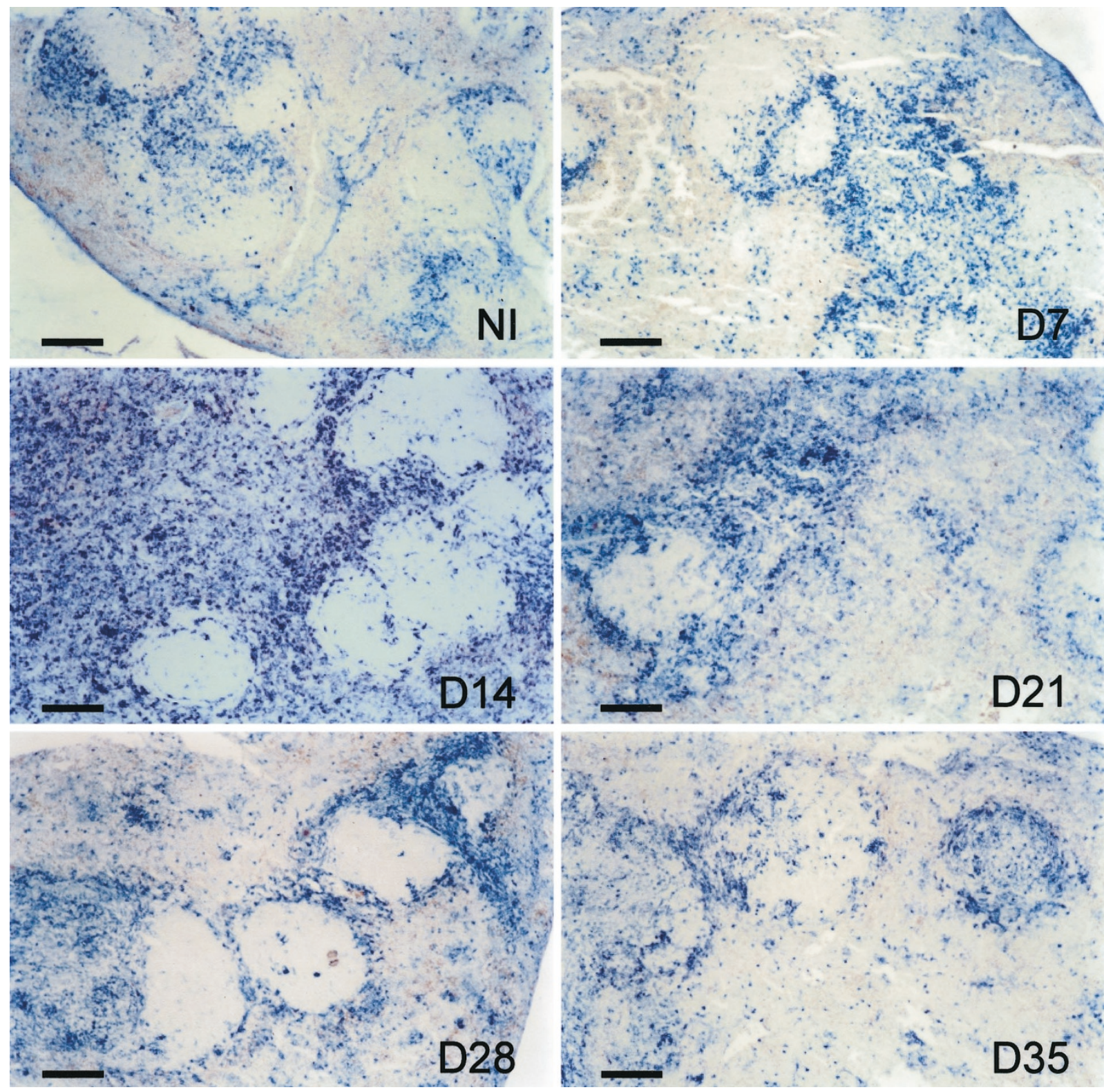

Figure 1.

T. cruzi infection increases the number of splenic dendritic cells $(\mathrm{sDC})$. Spleens were harvested from noninfected mice $(N I)$ and infected mice at Days $(D) 7,14,21$ 28 , and 35 pi. Sections were prepared, and SDC were stained in blue using an anti-CD11c mAb. Two mice were killed every week for immunohistochemical studies Representative data from one of two independent experiments are shown. Scale bar $=250 \mu \mathrm{m}$.

\section{T. cruzi Infection Inhibits the LPS-Mediated Migration/Maturation Process of $s D C$}

LPS is a well-known inducer of the DC migration/ maturation step (Buelens et al, 1997; De Smedt et al, 1997; Verhasselt et al, 1997). The effect of LPS on sDC in the course of $T$. cruzi infection has thus been investigated. For this, LPS has been injected into noninfected or infected mice at Day 14 pi (or at Day 21 pi) 6 hours before death. The response of sDC to LPS injection was evaluated in situ by immunohistochemistry by staining spleen sections as above. In noninfected mice, the LPS injection induced the redistribution of $\mathrm{B} .2^{+} \mathrm{sDC}$ that were mainly found in the T-cell zone (Fig. 3d). In clear contrast, such a redistribution did not occur when infected mice were treated with
LPS, either at Day 14 pi (Fig. 3e) or at Day 21 pi (Fig. 3f). Instead, sDC remained scattered outside the T-cell zone. In addition, LPS treatment induced the maturation of SDC that expressed B7.2 molecules at Day 14 pi (Fig. 3e). However, such LPS treatment did not induce this maturation step at Day $21 \mathrm{pi}$, and only B7.2 ${ }^{-}$sDC were detectable (Fig. 3f).

These data were confirmed by flow cytometry. The expression of B7.2 molecules was enhanced after LPS treatment in both noninfected and infected SDC at Day 14 pi (Fig. 4, A and B). However, when infected mice were treated with LPS at Day 21 pi instead of Day 14 pi, sDC were found to be resistant to the LPSmediated up-regulation of B7.2 expression (Fig. 4C). These data indicate that $T$. cruzi infection blocks the 

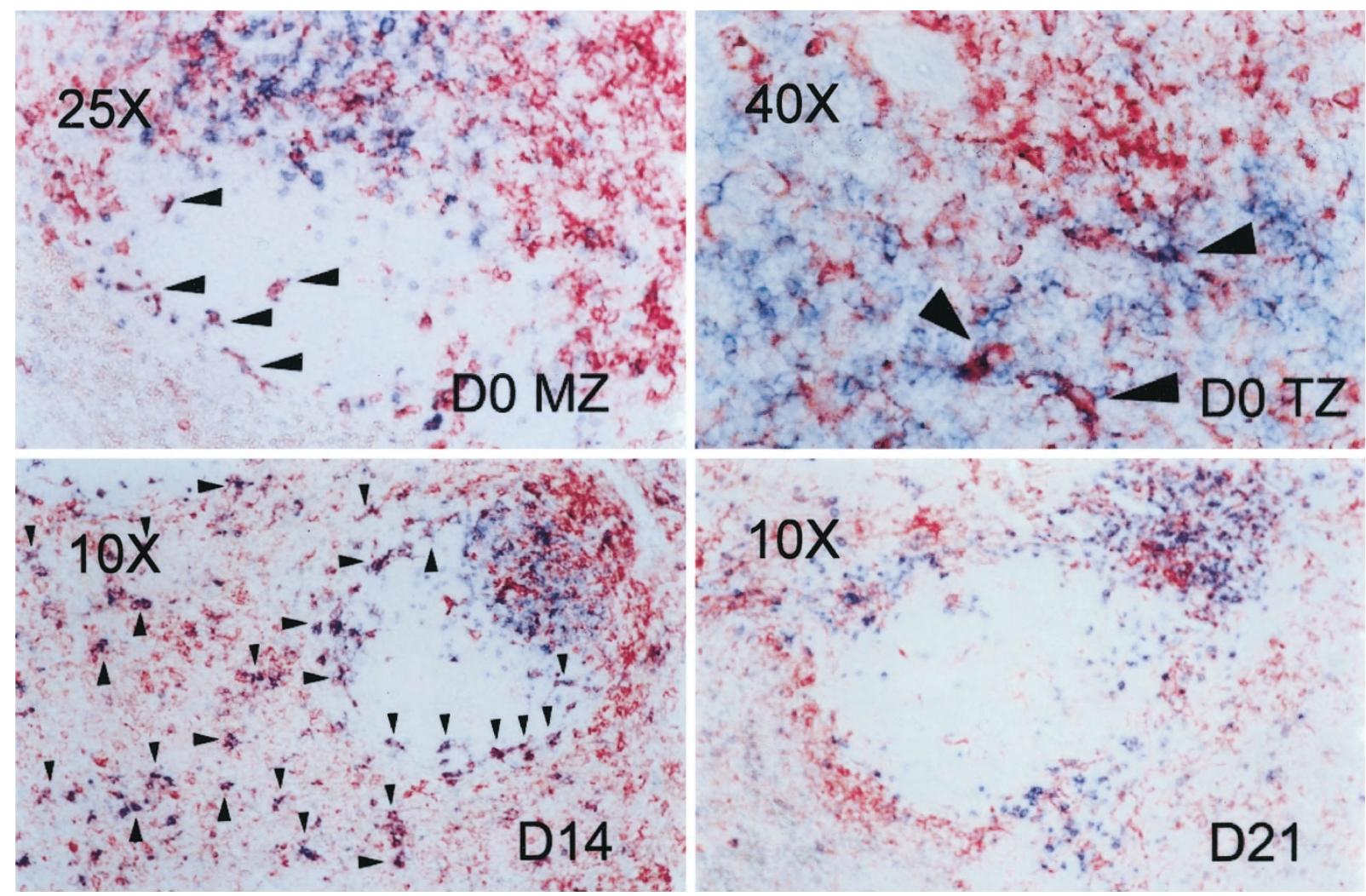

Figure 2.

T. cruzi infection down-regulates the $\mathrm{CD}^{+}$subclass of $\mathrm{SDC}$. $\mathrm{CD} 8^{-} \mathrm{CD} 11 \mathrm{C}^{+} \mathrm{SDC}$ (red), $\mathrm{CD} 8^{+}$cells (blue), and $\mathrm{CD}^{+} \mathrm{CD} 11 \mathrm{c}^{+} \mathrm{SDC}$ (purple, arrowhead) are shown $\mathrm{CD}^{+}{ }^{+} \mathrm{CD} 11 \mathrm{C}^{+} \mathrm{sDC}$ were seen in the marginal and T-cell zones before inoculation $(D O)$ and at Day $14 \mathrm{pi}$. At Day 14 pi, numerous $\mathrm{CD} 8^{-} \mathrm{CD}^{+} 1 \mathrm{C}^{+} \mathrm{SDC}$ and $\mathrm{CD} 8^{+} \mathrm{CD} 11 \mathrm{C}^{+}$ $\mathrm{SDC}$ are seen in the red pulp and in the marginal zone but not in the T-cell zone. At Day $21 \mathrm{pi}$, many SDC were present but CD8 ${ }^{+} \mathrm{CD} 11 \mathrm{c}^{+}$sDC disappeared completely $T Z=T$-cell zone; $M Z=$ marginal zone. Arrowhead: $\mathrm{CD} 8 \alpha^{+} \mathrm{CD} 11 \mathrm{c}^{+} \mathrm{SDC}$ in purple. Two mice were killed every week for immunohistochemical studies. Representative data from one of two independent experiments are shown. Scale bar $=250 \mu \mathrm{m}$.

LPS-induced migration/maturation process of SDC in the course of $T$. cruzi infection.

\section{T. cruzi Infection Reduces the Splenic T-Cell Population}

Because interactions between SDC and T- and B-cell populations are of a major importance in the establishment of protective adaptive immune responses, we further investigated $B$ and $T$ cells that were clearly detected at Days 0 (Fig. 5a) and 7 pi (not shown). However, as shown by immunohistochemistry, the T-cell population was dramatically depleted in the T-cell zone of the white pulp at Days 14, 21, and $28 \mathrm{pi}$ whereas the B-cell population remained unmodified (Fig. 5, b to d). Starting on Day $35 \mathrm{pi}$, the T-cell population was progressively restored (not shown). This feature corresponds to the end of the acute phase, the decline of parasitemia, and the beginning of the chronic phase in surviving mice. T-cell depletion in the T-cell zone was further confirmed by the decrease of both $\mathrm{CD}^{+}$and $\mathrm{CD}^{+}$cell populations at Day 21 pi in the T-cell area (Fig. 5, e and f).

\section{Kinetics of $S D C$ and $T$-Cell Populations in Relation to Parasitemia and Splenomegaly}

Kinetics studies were performed to further document the modification of SDC and T-cell populations in relation to parasitemia and splenomegaly. Both parasitemia and splenomegaly reached a plateau at Day 21 pi (Fig. 6, A and B). In two independent experiments, analysis by flow cytometry confirmed the data obtained by immunohistochemistry. The percentage of sDC increased starting on Day 14 until Day 35 pi and then progressively returned to a normal level (Fig. 6, C and $\mathrm{D}$ ). In contrast, the percentage of $\mathrm{CD}^{+} \mathrm{CD}^{+}$and $\mathrm{CD}^{+}{ }^{+} \mathrm{CD}^{+}{ }^{+} \mathrm{T}$ cells decreased between Days 14 and 21 and then progressively returned to normal (Fig. 6, C and D). Taken together, these results confirmed the immunohistochemical study indicating an increase of SDC and a depletion of T-cell populations during the acute phase of infection.

\section{Discussion}

Fully functional DC constitute an essential prerequisite to elicit an efficient immune response against pathogens. DC recruitment from the periphery (where antigens are acquired) to secondary lymphoid organs (where presentation occurs) is tightly associated with the maturation process. Migration and maturation of DC are important events because they augment DC accessory functions for optimal antigen presentation. Our observations demonstrate that $T$. cruzi did not induce the migration/maturation step of SDC. The 

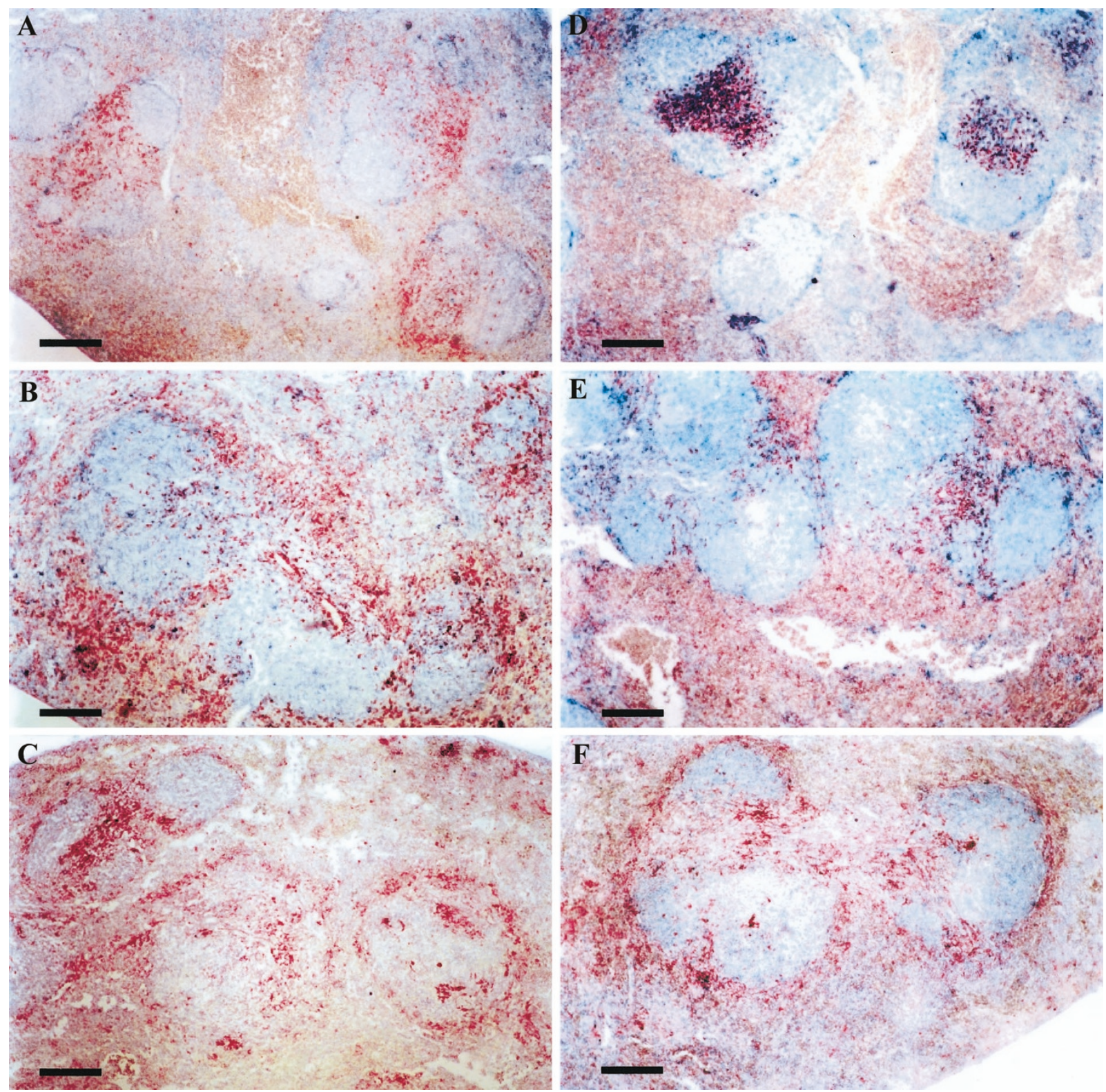

\section{Figure 3.}

T. cruzi infection modulates the migration/maturation step of SDC in nontreated and lipopolysaccharide (LPS)-treated infected mice. Spleens were harvested from noninfected mice (a) and from infected mice at Days 14 (b) or 21 (c) pi. In each group, other mice were intravenously injected with LPS 6 hours before death (d to f). Sections were prepared, and SDC were stained in red using an anti-CD11c mAb. B7.2 $2^{+}$cells were stained in blue. B7.2 $2^{+} \mathrm{CD} 11 \mathrm{c}^{+} \mathrm{SDC}$ appear in purple. Representative data from one of two independent experiments are shown. Scale bar $=250 \mu \mathrm{m}$.

absence of DC migration and maturation occurs during the acute phase of infection so that this absence could be dependent on the presence of parasites and/or on the release of factor(s) of parasitic origin as shown with the inhibition of T-lymphocyte activation, immunosuppression (Gomes et al, 1996; Kierszenbaum et al, 1998), anergy of CD4 ${ }^{+} \mathrm{T}$ cells (Millar et al, 1999), or alteration of DC and macrophage functions (Brodskyn et al, 2002; Van Overtvelt et al, 1999, 2002). $\mathrm{DC}$ are highly efficient APC involved in the priming of virtually any specific immune response. Our data show a sharp increase in the number of SDC by immunohistochemistry and by counting during the acute phase.
The percentage of SDC obtained by flow cytometry was also increased. These data are reminiscent of a recent report indicating that DC number was increased in mice at Day 14 post-immunization with cruzipain, a major antigen of $T$. cruzi (Giordanengo et al, 2002). Transient increase of SDC has also been reported some hours after injection of Toxoplasma gondii-derived antigen to mice (Sousa et al, 1999). These observations indicate that $T$. cruzi infection sharply enhances the number of SDC in parallel with the onset of parasitemia. Finally, SDC are involved, with other immunocompetent cells, in the increased cellularity seen in splenomegaly. However, the inhibi- 

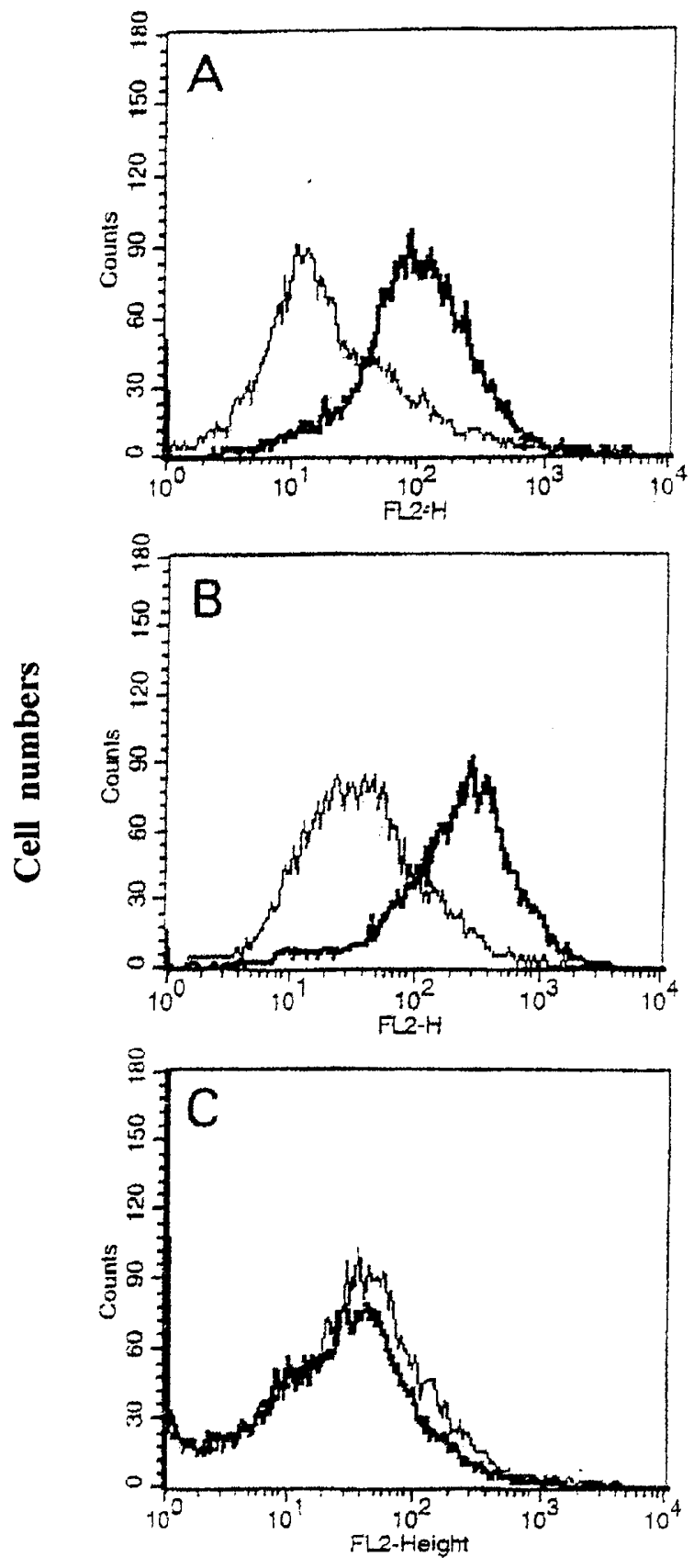

$\log _{10}$ Fluorescence

B7.2 (CD86)

Figure 4.

Expression of B7.2 by sDC isolated from LPS-treated and infected mice Days 14 or 21 pi. SDC from noninfected mice (A) and mice at Days 14 (B) or 21 (C) pi were positively separated over a N418 MACS column. In each experiment, some mice were treated with LPS 6 hours before death and SDC harvesting. Purified SDC were double stained for CD11c and B7.2. Data represent flow cytometry analysis of the expression of B7.2 of $\mathrm{CD} 11 \mathrm{c}^{+} \mathrm{SDC}$ from mice treated with LPS (thick line) or not (thin line). Representative data from one of three independent experiments are shown.

tion of their migration/maturation process suggests that they could not participate in the establishment of an effective immune response.
Our data are also reminiscent of an inhibitory effect on DC maturation that was found with other protozoan parasites such as Plasmodium falciparum (Urban et al, 1999) and T. gondii-derived antigen (Sousa et al, 1999). The existence of convergent mechanisms aiming to impair DC functions is of prime importance because it could provide a way for parasites to jeopardize the priming of specific immune responses. Once established, the anti-T. cruzi-specific immune response is responsible for the resolution of the acute phase (avoiding the host's death), but it fails to eliminate persistent infection (allowing the accomplishment of parasite life cycle). The priming of such responses can also be affected because the parasite impairs antigen-presenting capacities of macrophages or DC in both human and murine models (de Diego et al, 1997; La Flamme et al, 1997; Plasman et al, 1995; Van Overtvelt et al, 2002).

Finally, both $\mathrm{CD}^{+}$and $\mathrm{CD}^{+} \mathrm{T}$ cells play a major role in the immune response directed against $T$. cruzi (DosReis, 1997). Our data show a striking depletion of T cells by immunohistochemistry in the T-cell zone of the white pulp at Days 14 and 21 pi. This was confirmed by the reduced percentage of $T$ cells obtained by flow cytometry. These data are in line with a previous report showing that $T$. cruzi infection induced a strong reduction $(45 \%)$ in the percentage of splenic $T$ cells in the same experimental model (Tarleton et al, 1994; Vandekerckhove et al, 1994). In addition, as shown by immunohistochemistry, these modifications in T-cell number were associated with a spectacular modification of T-cell distribution: $\mathrm{CD}^{+}{ }^{+}$and $\mathrm{CD}^{+} \mathrm{T}$ cells were now present outside, not inside, the $T$ cell zone, and the white pulp center was filled with $\mathrm{CD} 4^{-} \mathrm{CD} 8^{-}$cells. Such a redistribution of $\mathrm{T}$ cells prevents $\mathrm{sDC} / \mathrm{T}$-cell interactions. The T-cell area progressively recovered its usual aspect during the chronic phase as shown at Day 98 pi. One can hypothesize that alteration of the migration/maturation process of SDC together with a dramatic depletion of $T$ cells prevents efficient contact between SDC and T cells, reinforces immunodepression, and thus favors the parasite invasion. This crucial step occurred during the development of the acute phase, and Day $21 \mathrm{pi}$ seems to be a critical moment of the infection, as previously suggested (Vandekerckhove et al, 1994). Nevertheless, the presence of $T$ cells at the beginning of the infection and the persistence of $B$ cells allows the development of a humoral response that is responsible for the decline of the acute phase. Indeed, the internalization of $T$. cruzi trypomastigotes by mouse peritoneal macrophages occurs via opsonic antibodies (Lages-Silva et al, 1987). A polyisotypic hypergammaglobulinemia and a stable polyisotypic parasite-specific response appears (el Bouhdidi et al, 1994), and specific anti-T. cruzi antibodies have a protective effect as shown by injecting immune serum prepared from immunized mice to $T$. cruzi-infected mice (Kierszenbaum and Howard, 1976).

Taking into account the central role of DC and T cells in the onset of efficient immune responses, alteration of the migration/maturation process to- 

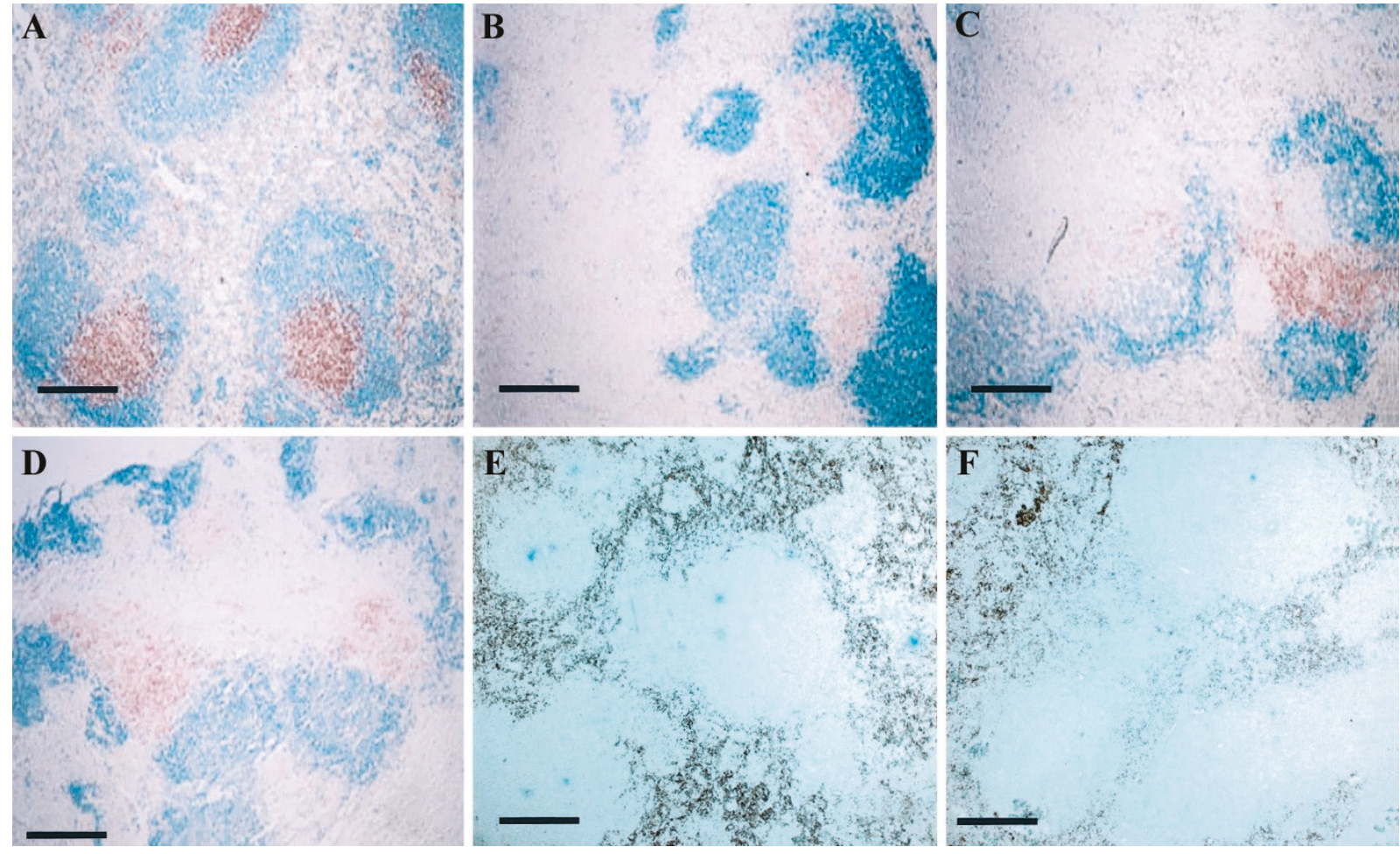

Figure 5.

T. cruzi infection reduces the T-cell population. Spleens were harvested from noninfected mice and mice at Days 14, 21, 28 pi (a to d). Sections were prepared, and $B$ and $T$ cells were stained, respectively, in blue and red using anti-B220 and anti-Thy.1.2. mAbs. CD4 ${ }^{+}$and CD8 ${ }^{+}$cells were stained in blue with anti-CD4 ${ }^{+}$and anti-CD8 ${ }^{+}$mAb (e and f, respectively) at Day 21 pi. Two mice were killed every week for immunohistochemical studies. Representative data from one of two independent experiments are shown. Scale bar $=250 \mu \mathrm{m}$.

gether with T-cell depletion/redistribution in the course of $T$. cruzi infection could be another strategy to escape immune surveillance and to persist in the mammalian host.

\section{Materials and Methods}

\section{T. cruzi Trypomastigotes and Infection of Mice}

T. cruzi trypomastigotes (Tehuantepec strain, Mexico) were maintained by weekly intraperitoneal inoculations into BALB/c mice (6-8 weeks old) purchased from Bantin \& Kingman Universal (Hull, United Kingdom) and maintained in our animal facilities on standard laboratory chow. To obtain large quantities of parasites, trypomastigotes $\left(2.5 \times 10^{5}\right.$ parasites/rat $)$ were inoculated into 7 Gy irradiated F344 Fischer rats (Iffa Credo, Brussels, Belgium). Trypomastigotes were obtained from the blood (containing $10 \mathrm{U}$ heparin/ml) of infected rats by ion exchange chromatography on diethylaminoethyl cellulose (Whatman DE 52) equilibrated with PBS glucose at pH 7.4 (Metz et al, 1993). Trypomastigotes were centrifuged (15 minutes, 1800 $\times g, 4^{\circ} \mathrm{C}$ ) and resuspended in endotoxin-free PBS. $\mathrm{BALB} / \mathrm{c}$ mice were inoculated intraperitoneally with 100 blood-form trypomastigotes in $0.2 \mathrm{ml}$ of Alsever's solution. Parasitemia was monitored by counting trypomastigotes in blood samples collected by tail incision every week pi. Survival rates were determined daily. To induce the SDC maturation step, LPS $(5 \mu \mathrm{g}$ in
$150 \mu$ I PBS, Escherichia coli 0111B4; Sigma Chemical Company, St. Louis, Missouri) was injected intravenously 6 hours before death. The maintenance and care of mice and rats complied with the guidelines of the Free University of Brussels Ethic Committee for the human use of laboratory animals.

\section{Immunohistochemical Studies}

Mice (50 animals per experiment) were killed by neck dislocation at various time intervals: $3,6,12$, and 24 hours pi and then every week at Day 7 until Day 98 pi. Spleens were harvested immediately after death and weighed. They were fixed for 3 days in Immunohistofix followed by dehydration in neat acetone for 6 hours. Tissues were embedded in Immunohistowax, sectioned at 3 to $6 \mu \mathrm{m}$, de-embedded by washing in acetone for 10 minutes, and transferred to PBS (Pajak et al, 2000). Noninfected mice served as control. sDC were stained using anti-CD11c mAb (clone N418, from our laboratory), anti-CD8 mAb (clone 53-6.7,) and antiB7.2 (CD86) mAb (clone GL1). B and T cells were stained using mAbs specific for B220/CD45R (RA3-GB2 clone) and Thy.1.2/CD90.2 (53-2.1 clone), respectively. All these clones were from BD-Biosciences-PharMingen.

\section{Obtainment of $S C$ and $S D C$}

Suspensions of SC were obtained by spleen dilaceration and treatment for 30 seconds with distilled sterile 

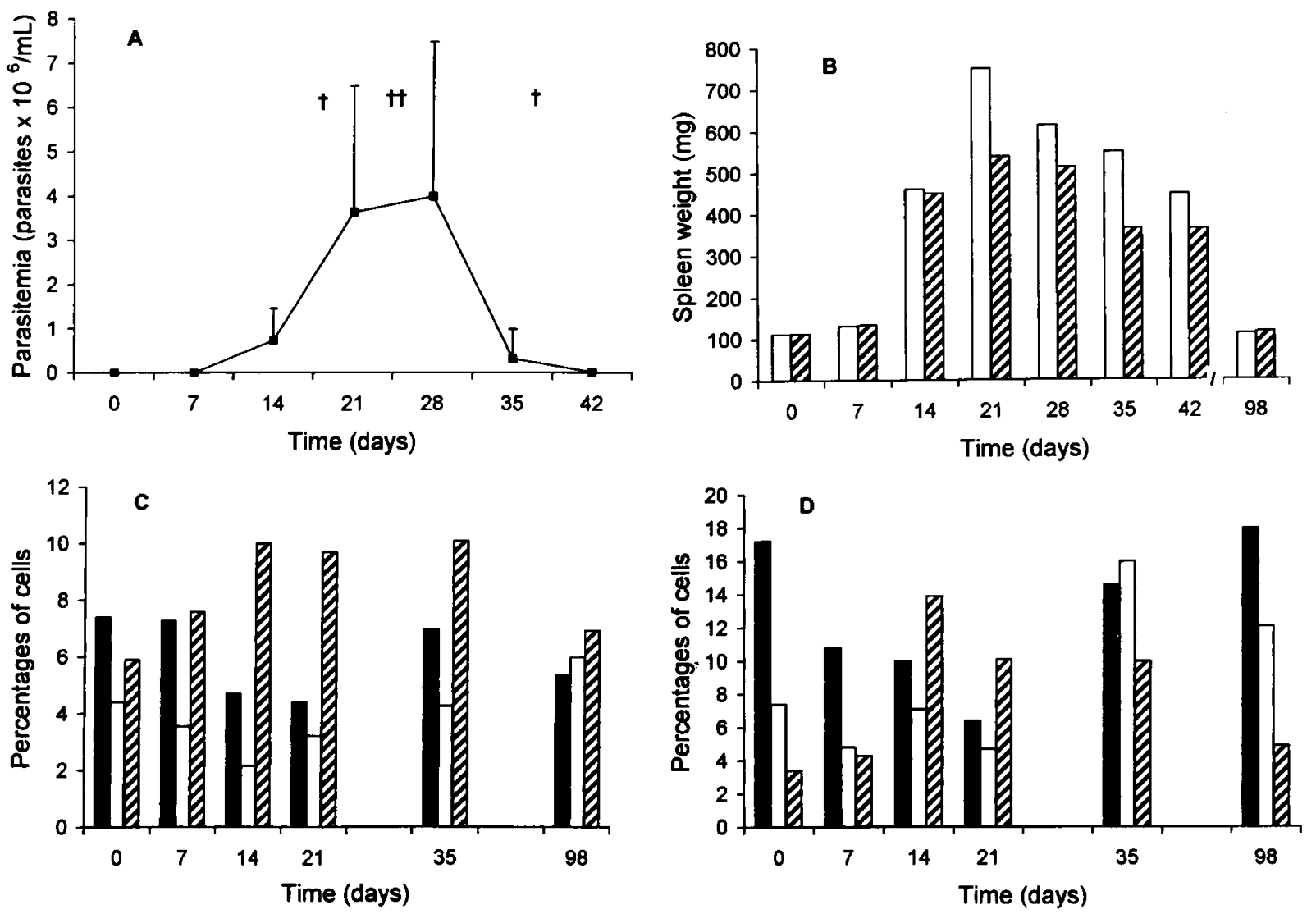

Figure 6 .

Kinetics of SDC and T-cell percentages in relation to parasitemia and splenomegaly. T. cruzi trypomastigotes were inoculated into a group of 20 mice (Day 0 ). The parasitemia (A) was recorded every week in surviving mice. Two mice were killed every week for immunohistochemical studies and spleen weight (two spleens per week; B). As a consequence, parasitemia (mean \pm SD) at Days 7, 14, 21, 28, 35, and 42 was calculated, respectively, with 20, 18, 15, 10, 7, and 6 mice. Mortality was recorded every day ( $\dagger=$ one dead mouse). $C$ and D, Mice (25 animals per experiment) were inoculated at Day 0 . Spleens were harvested, and SC were treated for flow cytometry with anti-CD11c or anti-CD3 + anti-CD4 or anti-CD3 + anti-CD8 mAb to determine cell percentage. Data from two independent experiments are shown. Black bars $=\mathrm{CD}^{+} \mathrm{CD}^{+}$cells; open bars $=\mathrm{CD}^{+} \mathrm{CD}^{+}$cells; hatched bars $=\mathrm{CD} 11 \mathrm{c}^{+} \mathrm{sDC}$.

water. SC were resuspended in RPMI 1640 medium (GIBCO), counted, and treated for flow cytometry (see below).

To isolate sDC, spleens were digested with collagenase, further dissociated in $\mathrm{Ca}^{2+}$ - and $\mathrm{Mg}^{2+}$ - free HBSS in the presence of ethylenediaminetetraacetic acid, and separated into low- and high-density fractions on a Nycodenz gradient. Low-density sDC were then incubated with anti-CD11c-coupled microbeads and positively separated over a MACS column (Miltenyi Biotec). Flow cytometry using FITC-conjugated $\mathrm{N} 418 \mathrm{mAb}$ indicated that samples contained at least 90\% positive cells.

\section{Flow Cytometry}

For immunophenotyping, SC were washed in PBS supplemented with $0.1 \%$ BSA (Sigma) and $10 \mathrm{~mm}$ $\mathrm{NaN}_{3}$. They were incubated with 2.4G2 (a rat antimouse Fc $\gamma R$ mAb from our laboratory) for 15 minutes at $4^{\circ} \mathrm{C}$ before staining to prevent antibody binding to Fc $\gamma \mathrm{R}$. Then they were incubated with $\mathrm{mAb}$ or with biotin-conjugated GL1 followed by phycoerythrin (PE)streptavidin. The following $m A b s$ were used to stain $\mathrm{sDC}, \mathrm{CD}^{+}, \mathrm{CD}^{+}$, and $\mathrm{CD}^{+}$cells: FITC-coupled
N418, FITC-coupled 145-2C11, PE-coupled RMA-5$\mathrm{PE}$, and PE-coupled 53-6.7, respectively.

\section{Acknowledgement}

We thank Ms. Iolanda Mazza for help in preparing the manuscript.

\section{References}

Abrahamsohn IA and Coffman RL (1995). Cytokine and nitric oxide regulation of the immunosuppression in Trypanosoma cruzi infection. J Immunol 155:3955-3963.

Andrade SG, Andrade V, Brodskyn C, Magalhaes JB, and Netto MB (1985). Immunological response of Swiss mice to infection with three different strains of Trypanosoma cruzi. Ann Trop Med Parasitol 79:397-407.

Brodskyn C, Patricio J, Oliveira R, Lobo L, Arnholdt A, Mendonca-Previato L, Barral A, and Barral-Netto M (2002). Glycoinositolphospholipids from Trypanosoma cruzi interfere with macrophages and dendritic cell responses. Infect Immun 70:3736-3743.

Buelens C, Verhasselt V, De Groote D, Thielemans K, Goldman $M$, and Willems $F$ (1997). Interleukin-10 prevents the generation of dendritic cells from human peripheral blood 
mononuclear cells cultured with interleukin-4 and granulocyte/macrophage-colony-stimulating factor. Eur J Immunol 27:756-762.

Camargo IJ, Araujo PM, Sakurada JK, Stach-Machado DR, and Rangel HA. (1991). Trypanosoma cruzi: Early resistance induced by culture-derived trypomastigotes. Exp Parasitol 73:260-268.

Cardillo F, Nomizo A, and Mengel J (1998). The role of the thymus in modulating gammadelta $\mathrm{T}$ cell suppressor activity during experimental Trypanosoma cruzi infection. Int Immunol 10:107-116.

Cerrone MC, Ritter DM, and Kuhn RE (1992). Effect of antigen-specific $\mathrm{T}$ helper cells or interleukin-2 on suppressive ability of macrophage subsets detected in spleens of Trypanosoma cruzi-infected mice as determined by limiting dilution-partition analysis. Infect Immun 60:1489-1498.

Chaussabel D, Jacobs F, de Jonge J, de Veerman M, Carlier Y, Thielemans K, Goldman M, and Vray B (1999). CD40 ligation prevents Trypanosoma cruzi infection through interleukin-12 upregulation. Infect Immun 67:1929-1934.

de Diego J, Punzon C, Duarte M, and Fresno M (1997). Alteration of macrophage function by a Trypanosoma cruzi membrane mucin. J Immunol 159:4983-4989.

De Smedt T, Pajak B, Muraille E, Lespagnard L, Heinen E, De Baetselier P, Urbain J, Leo O, and Moser M (1996). Regulation of dendritic cell numbers and maturation by lipopolysaccharide in vivo. J Exp Med 184:1413-1424.

De Smedt T, Pajak B, Muraille E, Urbain J, Leo O, and Moser $M$ (1997). Positive and negative regulation of dendritic cell function by lipopolysaccharide in vivo. Adv Exp Med Biol 417:535-540.

DosReis GA (1997). Cell-mediated immunity in experimental Trypanosoma cruzi infection. Parasitol Today 13:335-342.

el Bouhdidi A, Truyens C, Rivera MT, Bazin H, and Carlier Y (1994). Trypanosoma cruzi infection in mice induces a polyisotypic hypergammaglobulinaemia and parasite-specific response involving high IgG2a concentrations and highly avid IgG1 antibodies. Parasite Immunol 16:69-76.

Filgueira L, Nestle FO, Rittig M, Joller HI, and Groscurth P (1996). Human dendritic cells phagocytose and process Borrelia burgdorferi. J Immunol 157:2998-3005.

Giordanengo L, Guinazu N, Stempin C, Fretes R, Cerban F, and Gea S (2002). Cruzipain, a major Trypanosoma cruzi antigen, conditions the host immune response in favor of parasite. Eur J Immunol 32:1003-1011.

Gomes NA, Previato JO, Zingales B, Mendonca-Previato L, and DosReis GA (1996). Down-regulation of T lymphocyte activation in vitro and in vivo induced by glycoinositolphospholipids from Trypanosoma cruzi: Assignment of the T cell-suppressive determinant to the ceramide domain. J Immunol 156:628-635.

Goni O, Alcaide P, and Fresno M (2002). Immunosuppression during acute Trypanosoma cruzi infection: Involvement of Ly6G $(\mathrm{Gr} 1(+)) \mathrm{CD} 11 \mathrm{~b}(+)$ immature myeloid suppressor cells. Int Immunol 14:1125-1134.

Gorak PM, Engwerda CR, and Kaye PM (1998). Dendritic cells, but not macrophages, produce IL-12 immediately following Leishmania donovani infection. Eur J Immunol 28: 687-695.
Guarner J, Bartlett J, Zaki SR, Colley DG, Grijalva MJ, and Powell MR (2001). Mouse model for Chagas disease: Immunohistochemical distribution of different stages of Trypanosoma cruzi in tissues throughout infection. Am J Trop Med Hyg 65:152-158.

Henderson RA, Watkins SC, and Flynn JL (1997). Activation of human dendritic cells following infection with Mycobacterium tuberculosis. J Immunol 159:635-643.

Inaba K, Inaba M, Naito M, and Steinman RM (1993). Dendritic cell progenitors phagocytose particulates, including bacillus Calmette-Guerin organisms, and sensitize mice to mycobacterial antigens in vivo. J Exp Med 178:479-488.

Kierszenbaum F and Howard JG (1976). Mechanisms of resistance against experimental Trypanosoma cruzi infection: The importance of antibodies and antibody-forming capacity in the Biozzi high and low responder mice. J Immunol 116:1208-1211.

Kierszenbaum F, Majumder S, Paredes P, Tanner MK, and Sztein MB (1998). The Trypanosoma cruzi immunosuppressive factor (TIF) targets a lymphocyte activation event subsequent to increased intracellular calcium ion concentration and translocation of protein kinase $C$ but previous to cyclin D2 and cdk4 mRNA accumulation. Mol Biochem Parasitol 92:133-145.

Kierszenbaum F and Sztein MB (2001). Down-regulation of human B lymphocyte activities by a Trypanosoma cruzi membrane glycoprotein. Int J Parasitol 31:265-271.

La Flamme AC, Kahn SJ, Rudensky AY, and Van Voorhis WC (1997). Trypanosoma cruzi-infected macrophages are defective in major histocompatibility complex class II antigen presentation. Eur J Immunol 27:3085-3094.

Lages-Silva E, Ramirez LE, Krettli AU, and Brener Z (1987). Effect of protective and non-protective antibodies in the phagocytosis rate of Trypanosoma cruzi blood forms by mouse peritoneal macrophages. Parasite Immunol 9:21-30.

Lanzavecchia A and Sallusto F (2000). Dynamics of T lymphocyte responses: Intermediates, effectors, and memory cells. Science 290:92-97.

Liu YJ (2001). Dendritic cell subsets and lineages, and their functions in innate and adaptive immunity. Cell 106:259-262.

Lopes MF and DosReis GA (1996). Trypanosoma cruziinduced immunosuppression: Selective triggering of $\mathrm{CD}^{+}$ T-cell death by the T-cell receptor-CD3 pathway and not by the CD69 or Ly-6 activation pathway. Infect Immun 64:15591564.

Maldonado-Lopez R, De Smedt T, Michel P, Godfroid J, Pajak B, Heirman C, Thielemans K, Leo O, Urbain J, and Moser M (1999). CD8alpha+ and CD8alpha- subclasses of dendritic cells direct the development of distinct $T$ helper cells in vivo. J Exp Med 189:587-592.

Marinho CR, D'Imperio Lima MR, Grisotto MG, and Alvarez JM (1999). Influence of acute-phase parasite load on pathology, parasitism, and activation of the immune system at the late chronic phase of Chagas' disease. Infect Immun 67:308318.

Mellman I and Steinman RM (2001). Dendritic cells: Specialized and regulated antigen processing machines. Cell 106: 255-258. 
Metz G, Carlier Y, and Vray B (1993). Trypanosoma cruzi upregulates nitric oxide release by IFN-gamma-preactivated macrophages, limiting cell infection independently of the respiratory burst. Parasite Immunol 15:693-699.

Millar AE, Wleklinski-Lee M, and Kahn SJ (1999). The surface protein superfamily of Trypanosoma cruzi stimulates a polarized Th1 response that becomes anergic. J Immunol 162: 6092-6099.

Minoprio P, Bandeira A, Pereira P, Mota ST, and Coutinho A (1989). Preferential expansion of Ly-1 B and CD4- CD8- T cells in the polyclonal lymphocyte responses to murine Trypanosoma cruzi infection. Int Immunol 1:176-184.

Olivares FE, Heirman C, Thielemans K, and Vray B (1996). Granulocyte-macrophage colony-stimulating factor: Involvement in control of Trypanosoma cruzi infection in mice. Infect Immun 64:3429-3434.

Pajak B, De Smedt T, Moulin V, De Trez C, Maldonado-Lopez $\mathrm{R}$, Vansanten G, Briend $\mathrm{E}$, Urbain J, Leo O, and Moser M (2000). Immunohistowax processing, a new fixation and embedding method for light microscopy, which preserves antigen immunoreactivity and morphological structures: Visualisation of dendritic cells in peripheral organs. J Clin Pathol 53:518-524.

Plasman N, Guillet JG, and Vray B (1995). Impaired protein catabolism in Trypanosoma cruzi-infected macrophages: Possible involvement in antigen presentation. Immunology 86:636-645.

Sousa C, Yap G, Schulz O, Rogers N, Schito M, Aliberti J, Hieny S, and Sher A (1999). Paralysis of dendritic cell IL-12 production by microbial products prevents infection-induced immunopathology. Immunity 11:637-647.

Steinman RM, Pack M, and Inaba K (1997). Dendritic cells in the T-cell areas of lymphoid organs. Immunol Rev 156:25-37.

Tarleton RL (1988). Trypanosoma cruzi-induced suppression of IL-2 production. II. Evidence for a role for suppressor cells. $\mathrm{J}$ Immunol 140:2769-2773.

Tarleton RL and Kuhn RE (1983). Changes in cell populations and immunoglobulin-producing cells in the spleens of mice infected with Trypanosoma cruzi: Correlations with parasitespecific antibody response. Cell Immunol 80:392-404.

Tarleton RL, Sun J, Zhang L, and Postan M (1994). Depletion of T-cell subpopulations results in exacerbation of myocarditis and parasitism in experimental Chagas' disease. Infect Immun 62:1820-1829.
Tarleton RL and Zhang L (1999). Chagas disease etiology: Autoimmunity or parasite persistence? Parasitol Today 15: 94-99.

Urban BC, Ferguson DJ, Pain A, Willcox N, Plebanski M, Austyn JM, and Roberts DJ (1999). Plasmodium falciparuminfected erythrocytes modulate the maturation of dendritic cells. Nature 400:73-77.

Van Overtvelt L, Andrieu M, Verhasselt V, Connan F, Choppin J, Vercruysse V, Goldman M, Hosmalin A, and Vray B (2002). Trypanosoma cruzi down-regulates lipopolysaccharideinduced MHC class I on human dendritic cells and impairs antigen presentation to specific CD8(+) T lymphocytes. Int Immunol 14:1135-1144.

Van Overtvelt L, Vanderheyde N, Verhasselt V, Ismaili J, De Vos L, Goldman M, Willems F, and Vray B (1999). Trypanosoma cruzi infects human dendritic cells and prevents their maturation: Inhibition of cytokines, HLA-DR, and costimulatory molecules. Infect Immun 67:4033-4040.

Vandekerckhove F, Darji A, Rivera MT, Carlier Y, Vray B, Billiau A, and De Baetselier P (1994). Modulation of T-cell responsiveness during Trypanosoma cruzi infection: Analysis in different lymphoid compartments. Parasite Immunol 16: 77-85.

Verhasselt V, Buelens C, Willems F, De Groote D, HaeffnerCavaillon N, and Goldman M (1997). Bacterial lipopolysaccharide stimulates the production of cytokines and the expression of costimulatory molecules by human peripheral blood dendritic cells: Evidence for a soluble CD14dependent pathway. J Immunol 158:2919-2925.

von Stebut E, Belkaid Y, Nguyen BV, Cushing M, Sacks DL, and Udey MC (2000). Leishmania major-infected murine Langerhans cell-like dendritic cells from susceptible mice release IL-12 after infection and vaccinate against experimental cutaneous leishmaniasis. Eur J Immunol 30:34983506.

Younes-Chennoufi A, Hontebeyrie-Joskowicz M, Tricottet V, Eisen H, Reynes M, and Said G (1988). Persistence of Trypanosoma cruzi antigens in the inflammatory lesions of chronically infected mice. Trans R Soc Trop Med Hyg 82:7783. 